\title{
ALIMENTOS TRANSITÓRIOS E ALIMENTOS COMPENSATÓRIOS
}

\author{
Valéria Nahas Fagundes ${ }^{1}$
}

\section{INTRODUÇÃO}

A dignidade da pessoa humana - pilar fundamental da Constituição Cidadã - é a base de todas as grandes mudanças que se fizeram presentes em diversos campos do direito contemporâneo, notadamente no direito de família. Representa uma verdadeira cláusula geral de tutela da pessoa humana.

Presente de modo especial na Constituição da República, o princípio da proteção à pessoa humana altera o paradigma patrimonialista que despontou em toda a história do direito privado nacional anterior à década de 1990. Nos microssistemas montados para defesa de hipossuficientes (Código de Defesa do Consumidor, Estatuto da Criança e do Adolescente, Estatuto do Idoso, Lei dos Juizados Especiais Cíveis, Criminais e Federais), até os grandes sistemas como o Código Civil e o Código de Processo Civil, o tecido de toda a legislação pátria se forma a partir do atendimento a essa diretriz. Vê-se que, mesmo as legislações anteriores à Constituição Federal já expressavam essa

1 Bacharel em Ciências Jurídicas e Sociais pela Pontifícia Universidade Católica do Rio Grande do Sul (PUCRS), 2000. Licenciada em Letras, formação em Língua e Literatura Francesa pela PUCRS, 1986. Mestranda em Direito de Família na Universidade Federal do Rio Grande do Sul (UFRGS). Funcionária concursada, assessora da Terceira Vice-Presidência do Tribunal de Justiça do Rio Grande do Sul. 
preocupação, e os textos legais que, eventualmente, tenham manifestado qualquer angularidade com o texto constitucional, foram alterados ou, simplesmente, tidos por "não recepcionados" pela Carta Maior.

Dentre tantos, merece destaque o conceito de Sarlet (2002) quanto à dignidade da pessoa humana, segundo o qual se entende "[...] por dignidade da pessoa humana a qualidade intrínseca e distintiva de cada ser humano que o faz merecedor do mesmo respeito e consideração por parte do Estado e da comunidade, implicando, neste sentido, um complexo de direitos e deveres fundamentais que assegurem a pessoa tanto contra todo e qualquer ato de cunho degradante e desumano, como venham a lhe garantir as condições existenciais mínimas para uma vida saudável, além de propiciar e promover sua participação ativa e corresponsável nos destinos da própria existência e da vida, em comunhão com os demais seres humanos". ${ }^{2}$

Seguindo uma tendência maciça no mundo ocidental, a lei brasileira reconhece direitos impondo comportamentos (deveres) aos sujeitos sociais interrelacionados. A sociedade reconhece justas expectativas nos relacionamentos - seja como eles se estabeleçam - e o descumprimento desses deveres pode acarretar sanções legais as mais diversas.

A legislação nacional, acompanhada da doutrina e da jurisprudência, está francamente aberta aos mais diferentes tipos de relacionamentos interpessoais, reconhecendo como entidades familiares composições que seriam impensáveis aos olhos da legislação anterior. A partir da Constituição Federal, a proteção do Estado não se restringe a um standart familiar único, fundado no casamento. Grupamentos familiares, que destoam do modelo anterior, alcançaram a mesma proteção, na busca da melhor efetivação possível das garantias da dignidade da pessoa humana.

Contudo, mesmo que a legislação nacional não leve em consideração os motivos que levam os integrantes da família a estabelecer esse ou aquele projeto familiar, em caso de ruptura do liame conjugal, essa estrutura pode ser relevante para definir os direitos dos ex-cônjuges depois da separação. Em verdade, é no momento de ruptura, quando além do abandono do projeto de vida em comum é normal que o casal agora separado entrave disputas as mais variadas quanto a bens, à guarda dos filhos e, especialmente, à divisão do patrimônio e ao estabelecimento da forma de mantença de cada

2 SARLET, Ingo. Dignidade da Pessoa Humana e Direitos Fundamentais. 2. ed. Porto Alegre: Livraria do Advogado, 2002. p. 62. 
um, que o direito se faz mais necessário, para o reajuste familiar.

No presente artigo, faremos uma breve consideração a respeito do princípio da dignidade da pessoa humana. Discorreremos sobre a igualdade formal dos cônjuges e a necessidade de equiparação fática (ou diminuição de desigualdades). Explanaremos sobre o estabelecimento do direito a alimentos transitórios ou a alimentos compensatórios. Estabeleceremos, de maneira simplificada, a distinção entre os dois institutos. Teceremos considerações acerca dos requisitos para a concessão desse tipo de alimentos.

\section{DA DIGNIDADE DA PESSOA HUMANA COMO LIMITES DE FIXAÇÃO DE ALIMENTOS}

Como veremos no próximo tópico, o conceito jurídico de alimentos não se restringe ao provimento de comida. Muito mais amplo, está umbilicalmente ligado à noção de vida digna.

A dignidade da pessoa humana, desde 1988 tutelada pela nossa Constituição da República, teve seu conceito guindado a princípio fundamental, alcançando todo e qualquer indivíduo integrante da sociedade. Liga-se a outros princípios na efetivação do fortalecimento social através da valorização da pessoa.
Embora se reconheça a dificuldade do estabelecimento de um conceito unívoco de dignidade da pessoa humana, está empiricamente introjetada em cada cidadão a noção de respeito a sua forma de ser, de viver (desde que não traga prejuízos à sociedade como um todo). Toda pessoa é digna, fazendo existir a condição de vários direitos fundamentais, o objetivo se perfaz pela proteção e abominação de qualquer forma de dominação que o Estado ou qualquer outro indivíduo queira possuir diante seus direitos.

A proteção da dignidade da pessoa humana é, pois, o fim a que se busca com o estabelecimento dos alimentos. Sejam os alimentos prestados com base na autoridade parental, sejam os direcionados ao ex-cônjuge, os alimentos prestados a irmãos em necessidade, ou alimentos devidos por avós em razão da impossibilidade de os pais suportarem o encargo. Em qualquer hipótese, o fim a que se busca é o respeito a cada indivíduo para fortalecer a sociedade toda.

\section{CONCEITO DE ALIMENTOS}

Qualquer reflexão sobre alimentos deve partir da definição de Yussef Said Cahali (2009), na clássica obra Dos Alimentos: "os alimentos são prestações devidas, feitas para que aquele que as recebe possa subsistir, isto é, manter sua existência, realizar 
o direito à vida, tanto física (sustento do corpo) como intelectual e moral (cultivo e educação do espírito, do ser racional). Assim, constituem os alimentos uma modalidade de assistência imposta por lei, de ministrar os recursos necessários à subsistência, à conservação da vida, tanto física como moral e social do indivíduo".

Para Silvio de Salvo Venosa (2008, p. 348): "alimentos, na linguagem jurídica, possuem significado bem mais amplo do que o sentido comum. Compreendendo, além da alimentação, também o que for necessário para moradia, vestuário, assistência médica e instrução".

Também na voz de Orlando Gomes (1999, p. 427): “alimentos são prestações para satisfação das necessidades vitais de quem não pode provê-las por si”".

Na clássica divisão adotada por Cahali (2009, p. 18-27), os alimentos podem ser classificados quanto à natureza (naturais ou civis), quanto à causa jurídica (decorrentes da lei, da vontade ou de delito), quanto à finalidade (provisionais ou regulares), quanto ao momento da prestação (futuros ou pretéritos) e quanto à modalidade da obrigação (própria ou imprópria).

De todas as definições acima extrai-se o fundamento axiológico da obrigação alimentícia: o direito à vida, e a sua medida se dá pela afirmação do princípio da dignidade da pessoa humana. Assim, o instituto dos alimentos existe para garantir a vida, e é mensurado de forma a garantir a dignidade.

Vê-se, portanto, que se trata de um dos institutos basilares do direito de família, garantindo ao alimentando - que pode ser cônjuge, ex-cônjuge ou parente - subsistência, manutenção, a criação, educação, saúde e recreação do beneficiado. Diz não só com a subsistência material, como também com a formação intelectual. É o instrumento legal chave para assegurar vida digna aos que não conseguem prover o próprio sustento.

Para satisfazer tal intuito, a fixação dos alimentos se revela uma tarefa difícil, tendo em vista o caráter abstrato e casuístico da obrigação alimentar.

Tradicionalmente, a fixação dos alimentos segue, segundo a doutrina e a jurisprudência, o binômio necessidade/possibilidade.

Contudo, o Código Civil impõe o dever de fixação proporcional entre as necessidades do alimentado e as possibilidades do(s) alimentante(s).

Nessa pespectiva, leciona Dias (2005, p. 544):

Tradicionalmente, invoca-se o binômio necessidade-possibilidade, ou seja, perquirem-se as necessidades do alimentando e as possibilidades do alimentante para estabelecer o valor da pensão. No entanto, essa mensuração é feita para que se res- 
peite a diretriz da proporcionalidade. Por isso se começa a falar, com mais propriedade, em trinômio: proporcionalidade-possibilidade-necessidade.

Com essas balizas, verifica-se que a imposição de prestação de alimentos possui como finalidade última a preservação do valor social mais caro à pessoa humana: a vida. Inafastável, nessa lógica, a percepção ética da prestação alimentar, na busca da preservação de uma vida digna do alimentado, sem prejuízo da subsistência - e também manutenção de uma vida digna - por parte do alimentante.

A vida, contudo, é dinâmica e não necessariamente as situações de necessidade alimentar e possibilidade de prestar alimentos se mantêm inalteradas. Com vistas a essa realidade, a legislação disciplinou hipóteses de revisão ou extinção da obrigação alimentar.

São causas da extinção automática da obrigação alimentar a extinção do poder familiar e a morte do alimentante.

Além das causas automáticas de extinção da obrigação, situações específicas fáticas que alterem a harmonia do binômio necessidade/possibilidade podem autorizar a extinção ou redução do pensionamento.

Contudo, há hipóteses em que as partes envolvidas, de comum acordo, podem estabelecer um período de duração para o pensionamento. Período esse normalmente projeta- do para permitir ao alimentante que estabeleça ou restabeleça condições de prover seu próprio sustento. Também assim, em hipóteses judicializadas é autorizado ao magistrado fixar um tempo de duração para a prestação alimentar. Os critérios para o estabelecimento judicial de um termo final para o pensionamento são, naturalmente, os mesmos para a fixação do valor, equacionados sob a ótica de um prazo razoável para que se alterem as premissas. Sobre o tema, trataremos a seguir.

\section{DOS ALIMENTOS TRANSITÓRIOS}

Alimentos transitórios são os alimentos devidos, por prazo certo, a excônjuge. Podem ser fixados por decisão judicial ou acordados pelo casal no momento da separação - ou até durante a constância da união conjugal.

Na lição da Ministra Nancy Andrighi, alimentos transitórios "possuem cunho resolúvel, e são obrigações prestadas especialmente entre ex-cônjuges ou ex-companheiros, em que o credor, em regra pessoa com idade apta para o trabalho, necessita dos alimentos apenas até que se projete determinada condição ou final de certo tempo, circunstância em que a obrigação extinguir-se-á automaticamente" (RESp 1388955, Terceira Turma, DJe em 29/11/2013). 
Embora não haja previsão no nosso ordenamento para o pagamento de alimentos a termo certo, tanto a doutrina como a jurisprudência entendem como válida a fixação judicial da prestação alimentícia com prazo fixado por acordo ou decisão judicial.

A lógica do entendimento se funda na previsão de mudança dos critérios pelos quais se estabeleceu o valor do pensionamento: em um tempo determinado, o alimentante poderá arcar com sua própria mantença.

Assim, alimentos transitórios são aqueles fixados ao ex-cônjuge ou ao ex-companheiro durante prazo certo. Como o direito a alimentos não dá garantia de pensionamento eterno, podendo ser revisto ou extinto de acordo com as circunstâncias pessoais dos envolvidos na prestação, a peculiaridade dessa forma de pensionamento não está no fato de haver um termo, mas, sim, de haver um tempo certo, prefixado. É feita uma projeção do período necessário para que o alimentando possa restabelecer (ou estabelecer) suas condições de sustento e, eventualmente, de contribuir para o sustento da prole.

A hipótese da fixação excepcional depende de certas circunstâncias: o alimentando deve, em primeiro lugar, possuir condições de adquirir trabalho capaz de manter o próprio sustento. Isso implica, evidentemente, que o alimentando que, por qualquer motivo, ao momento da separação não pode arcar com seu sustento, tenha condições de idade, saúde e qualificação profissional para, em curto espaço de tempo, buscar esse sustento no mercado de trabalho.

Veja-se, em recente decisão:

RECURSO ESPECIAL. PROCESSO CIVIL. EXECUÇÃO DE ALIMENTOS TRANSITÓRIOS. PROCEDIMENTO ADEQUADO. RITO DA PRISÃO ESTABELECIDO NO ART. 733 DO CPC.

1. Execução de alimentos ajuizada em 21/09/2010, da qual foi extraído o presente recurso especial, concluso ao Gabinete em 09/07/2013.

2. Discute-se o procedimento adequado à execução de alimentos transitórios.

3. A obrigação de prestar alimentos transitórios - a tempo certo - é cabível, em regra, quando o alimentando é pessoa com idade, condições e formação profissional compatíveis com uma provável inserção no mercado de trabalho, necessitando dos alimentos apenas até que atinja sua autonomia financeira, momento em que se emancipará da tutela do alimentante - outrora provedor do lar -, que será, então, liberado da obrigação, a qual se extinguirá automaticamente. Precedentes.

4. Hipótese em que a fixação de valor elevado da obrigação alimentar está ligada à distinta situação de demora verificada na partilha dos bens do casal, possuindo, assim, os alimentos natureza jurídica própria, porque estabelecidos em razão de uma causa temporária e específica.

5. Se assim o é, porque dotados de caráter efêmero, os alimentos transi- 
tórios ou, mais precisamente, a obrigação à sua prestação imprescindivelmente deve estar acompanhada de instrumentos suficientemente eficazes à sua consecução prática, evitando que uma necessidade específica e temporária se transfigure em uma demanda perene e duradoura ou, ainda, em um benefício que nem sequer o alimentado queira dele usufruir.

6. Na espécie, a busca, já longa e cansativa, da recorrente pelo encerramento do vínculo - patrimonial que ainda nutre, à sua contra vontade, com o recorrido encontra amparo inclusive na Constituição Federal, que assegura a liberdade e a independência da mulher, enquanto ser de iguais direitos e obrigações do homem (art. $5^{\circ}$, caput e inc. I, CF/88).

7. A pretensão da recorrente de demandar pela partilha do patrimônio que lhe é devido deve ser albergada não por altruísmo ou outro sentimento de benevolência qualquer, mas sim pelo fato de ser ela também proprietária do que construiu em igualdade de forças com o recorrido.

8. Impõe-se conceber que, sem prejuízo ao disposto no enunciado $\mathrm{n}^{\mathrm{o}}$ 309 da Súmula/STJ, somente o rito da execução cumulado com a prisão (art. 733, CPC) é o adequado para plena eficácia da decisão que conferiu, em razão da desarrazoada demora na partilha de bens do casal litigante, alimentos transitórios em valor suficiente à composição definitiva do litígio instalado entre as partes e, ainda, para que a situação outrora tida por temporária não se eternize no tempo. 9. Recurso especial provido.

(REsp 1362113/MG, Rel. Ministra NANCY ANDRIGHI, TERCEIRA
TURMA, julgado em 18/02/2014, DJe 06/03/2014.)

O entendimento jurisprudencial é que uma das características da obrigação alimentar é a sua condicionalidade à permanência de seus requisitos: vínculo de parentesco, conjugal ou convivencial; necessidade e incapacidade, ainda que temporária, do alimentando para sustentar-se; e possibilidade do alimentante de fornecer a prestação.

Assim, o direito à pensão alimentícia, que possui em sua gênese uma espécie de natureza indenizatória pela quebra da segurança estabelecida pelo casamento - a legislação anterior inclusive perquiria o titular da culpa pela separação - é baseado no binômio necessidade/possibilidade e, eventual transitoriedade dos alimentos, não altera essa lógica.

A questão da transitoriedade, em que tempo ou condição põem termo à obrigação, não altera as características da prestação alimentar.

Em situações específicas - a regra é a não fixação de termo final para a obrigação - o Superior Tribunal de Justiça reconhece como válida a fixação de pensão alimentícia mensal por um período médio de dois anos, a contar do trânsito em julgado da decisão que a fixou, em favor de ex-cônjuge que, embora não tenha exercido atividade remunerada durante a constância do casamento, detém idade e condições para o trabalho e, dentro 
desse período, será capaz de produzir condições de se manter.

Os alimentos - por regra - são personalíssimos, irrenunciáveis, recíprocos, intransmissíveis, impenhoráveis, irrepetíveis, imprescritíveis, incompensáveis, atuais, futuros e periódicos e eventual descumprimento da obrigação sujeita o devedor à prisão. Os alimentos transitórios possuem as mesmas características.

Leciona a Ministra Nancy Andrighi, que os alimentos transitórios têm natureza jurídica própria, porque são estabelecidos em razão de uma causa temporária e específica.

Em outras palavras, "a obrigação de prestar alimentos a tempo certo é cabível, em regra, quando o alimentado é pessoa com idade, condições e formação profissional compatíveis com uma provável inserção no mercado de trabalho, necessitando dos alimentos apenas até que atinja sua autonomia financeira" (REsp 1.025.769).

Importa destacar que o conceito de alimentos transitórios não se confunde com o de alimentos provisórios.

Já está cristalizado entre os operadores do direito que a concessão de alimentos provisórios durará até decisão judicial transitada em julgado, momento em que os alimentos serão definitivos (se a sentença os considerou devidos) ou serão extintos (se a sentença os considerou indevidos). Sobre o tema, Theodoro Jr. (2007, p. 682):
[...] nos casos enquadrados na Lei $\mathrm{n}^{\circ} 5.478$ (ações de alimentos, separação judicial e anulação de casamento), os alimentos provisórios serão devidos até a decisão final, inclusive o julgamento do recurso extraordinário (art.13, § $3^{\circ}$ ), confirmando a existência do princípio da transitoriedade dos alimentos enunciados nos artigos 1.699 e 1.708 do Código de Processo Civil, no qual está expressa a exoneração e a cessão da prestação de alimentos.

\section{CONCEITO DE ALIMENTOS COMPENSATÓRIOS (OU SOCIAIS)}

Os alimentos compensatórios ou sociais são prestações fundamentadas no vínculo de solidariedade e no dever de assistência mútua entre cônjuges (ou companheiros), com vistas à manutenção da dignidade do casal mesmo depois da separação.

Ou seja, à mingua de legislação específica, a doutrina e a jurisprudência brasileiras tem-se ocupado em reequilibrar a posição econômica dos cônjuges ou companheiros desencadeada pela ruptura convivencial, não apresentando como requisito a necessidade do alimentado, mas, sim, uma situação de desequilíbrio.

Os alimentos compensatórios decorrem da boa-fé objetiva presente na construção familiar quando o estabelecimento do modelo familiar e o comportamento das partes gerou 
uma justa expectativa de manutenção mesmo no caso de uma dissolução. Dessa maneira, é possível defender os alimentos em perspectiva compensatória, fixados em valor proporcional ao padrão de vida mantido anteriormente. Visa equiparar a disparidade gerada no status econômico e social do ex-cônjuge pelo divórcio.

Tendem à transitoriedade e, por possuírem caráter personalíssimo, os alimentos compensatórios não podem ser objeto de cessão de direito e nem tampouco são transmissíveis hereditariamente.

O grande doutrinador sobre o tema, no Brasil, é Rolf Madaleno, que estudando o direito comparado passou a defender, também para o Brasil, a adoção do instituto.

Jorge O Azpiri , citado por Madaleno (2004)

[...] define a pensão compensatória no direito espanhol como uma prestação periódica em dinheiro, efetuada por um cônjuge em favor do outro esposo, por ocasião da separação ou do divórcio vincular, em que se produza desequilíbrio econômico em comparação com o estilo de vida experimentado durante a convivência matrimonial, compensando deste modo, a sensível disparidade que o separando alimentário irá deparar com a separação em sua padronagem social e econômica, comprometendo, com a ruptura das núpcias, os seus compromissos materiais, seu estilo de vida, e a sua própria subsistência.
Em que pese a grande relevância outorgada ao tema pela doutrina e pela jurisprudência, primeiramente importa referir que a nomenclatura utilizada demanda considerações.

Simão (2013) é uma das vozes que se manifestam contrárias à nomenclatura e à própria aplicação do instituto. No livro Alimentos compensatórios: desvio de categoria e um engano perigoso, o autor manifesta entendimento de que a nomenclatura conduz a desnecessários equívo$\cos$, tendo em vista a clara natureza indenizatória da pretensão. A natureza pseudoalimentar poderia induzir desdobramentos jurídicos incabíveis, como o pedido de prisão nas hipóteses de descumprimento da obrigação. Em breves palavras, o autor aponta os seguintes impedimentos para a aplicação do instituto:

1. A noção clássica de alimentos, adotada no nosso país, associa a verba alimentar à manutenção da vida, no sentido mais amplo da palavra, em termos materiais, morais e sociais de um indivíduo, como decorrência de sua necessidade e levando em consideração as possibilidades daquele que tiver que prestar os alimentos.

2. O instituto não se molda às características básicas do conceito de alimentos: irrenunciabilidade, intransmissibilidade, impenhorabilidade, 
natureza não transacionável, impossibilidade de compensação e imprescritibilidade.

3. A ausência de disciplinamento legal não deixa estabelecer um critério uniforme para lhes emprestar fundamento jurídico, o que pode levar à aplicação dessa figura jurídica "a duas situações completamente diversas", sendo o instituto profundamente permeável à casuística.

Vozes mais consentâneas com a tendência mundial ocidental, contudo, defendem o instituto. O entendimento funda-se no princípio social da dignidade da pessoa humana.

As diversas formas de conjugação familiar, aceitas pela sociedade, quando desfeitas não podem levar a uma solução única. As peculiaridades do arranjo familiar, quando da separação - especialmente naquelas em que o casamento durou muitos anos - podem levar a situações em que uma das partes, no mais das vezes a mulher, fica sem a menor condição de manter status semelhante ao que vivia o casal. A fixação de alimentos compensatórios busca evitar uma enorme queda nas condições de vida por causa do fim da união.

Leciona a ilustre professora doutora Regina Beatriz Tavares da Silva:

Os prejuízos que são ressarcidos com a prestação compensatória advêm do enriquecimento sem causa, ou seja, do fato de um dos cônjuges, na dissolução do casamento, enriquecer-se à custa do outro, porque recebeu dele auxílio em sua ascensão profissional, e contribuiu para o seu progresso, inclusive em razão da dedicação que o outro cônjuge deu à educação dos filhos comuns, deixando de progredir na mesma medida que o devedor da prestação compensatória, ou mesmo porque, após a dissolução, o credor dessa prestação não gozará mais dos benefícios, inclusive patrimoniais do outro cônjuge.

Na mesma linha, Dias (2009):

Produzindo, a separação ou o divórcio, desequilíbrio econômico entre o casal em comparação com o padrão de vida de que desfrutava a família, cabível a fixação dos alimentos compensatórios. Faz jus a tal verba o cônjuge que não perceber bens, quer por tal ser acordado entre as partes, quer em face do regime de bens adotado no casamento, que não permite comunicação dos aquestos. Em decorrência do dever de mútua assistência (CC 1.566 III), os cônjuges adquirem a condição de consortes, companheiros e responsáveis pelos encargos de família (CC 1.516). Surge, assim, verdadeiro vínculo de solidariedade (CC 265), devendo o cônjuge mais afortunado garantir ao ex-consorte alimentos compensatórios, visando a ajustar o desequilíbrio econômico e a reequilibrar suas condições sociais. Dispõem, assim, os alimentos compensatórios de nítido caráter indenizatório, não se sujeitando a variações. Como não tem conteúdo alimentar, o encargo não se submete a variações. 
Como não tem conteúdo alimentar, o encargo não se submete às vicissitudes do trinômio proporcionalidadenecessidade-possibilidade. Dessa forma, mesmo que o beneficiário venha a obter meios de prover a sua própria subsistência, tal não dispensa o devedor de continuar alcançando-lhe alimentos.

Indispensável, por todos, a lição de Madaleno:

Conforme Jorge O. Azpiri, um dos cônjuges pode ser obrigado a abonar o outro com uma prestação destinada a compensar, até onde for possível, a disparidade material causada pela ruptura do relacionamento, e neste sentido difere sensivelmente da pensão transitória, esta última com larga aplicação nas dissensões conjugais, mesmo sem expressa previsão legal, por considerar a necessidade passageira do alimentando. Outro é o propósito da pensão compensatória que equilibra o padrão econômico-financeiro, servindo quase que para indenizar a perda do padrão social causada pela separação ou divórcio.

Assim, independente da nomenclatura, fica clara a intenção dos defensores da teoria: o objetivo dos alimentos compensatórios é indenizar o cônjuge que, por qualquer motivo, ficou sujeito ao desempenho profissional do outro durante a união e, com a separação, se não houver o pensionamento, vivenciará situação insuperável. Visa reequilibrar, na medida do possível, eventuais dispari- dades econômicas que venham a ser desencadeadas pelo rompimento da união conjugal. Não pretende custear despesas de sustento e sobrevivência do outro cônjuge, mas, sim, a manutenção de um padrão social que, na cultura ocidental, se confunde com a manutenção de um padrão social de dignidade estabelecido. Os alimentos compensatórios consubstanciam-se na entrega de um capital, em dinheiro ou bens, àquele cônjuge ao qual a separação prejudicou mais financeiramente.

Em resumo, a prestação compensatória, ou "por desequilíbrio" advém da constatação objetiva da existência de um desequilíbrio econômico derivado da ruptura da união conjugal e busca reequilibrar essa situação, restaurando o estilo de vida que o cônjuge prejudicado desfrutava na constância da união, como destaca Madaleno: “[...] não porque devam seguir vivendo da mesma maneira, mas, sim, porque um dos cônjuges não pode descer em sua condição econômica enquanto o outro mantém idêntica situação já existente antes da separação".

\section{PRESSUPOSTOS \\ PARA CONCESSÃO \\ E QUANTIFICAÇÃO \\ DOS ALIMENTOS COMPENSATÓRIOS}

Levam-se em consideração - dentre outros eventualmente pertinentes 
ao caso concreto, os seguintes pressupostos para concessão dos alimentos compensatórios:

1. a duração do casamento;

2. a idade dos cônjuges;

3. o estado de saúde dos cônjuges;

4. a qualificação profissional e acadêmica dos cônjuges; e,

5. a probalidade do efetivo (re) ingresso no mercado de trabalho.

Os critérios acima, analisados conjuntamente com a situação patrimonial de cada cônjuge, no início da vida conjugal e no momento da separação, devem ser analisados pelo juízo antes da fixação de possível indenização. Verificará igualmente chances perdidas por cada um dos cônjuges, em razão da união; o que cada um deixou de produzir ou ganhar em face de escolhas de vida feitas pelo casal.

Colocada assim a questão, resta claro que o direito à pensão compensatória é direito pessoal do cônjuge que não conseguiu investir no seu crescimento pessoal por causa da união e que, com a separação, terá diminuído seus status econômico em relação ao que usufruía na constância do casamento.
Estabelecido o direito à indenização, o pagamento pode ser fixado em uma única prestação ou em pagamentos sucessivos. Pode, ainda, ser temporário ou sem termo final, sendo, nessa última hipótese, extinto somente com a alteração das variáveis que determinaram o pensionamento.

Necessário referenciar que a concessão de alimentos compensatórios não repristina qualquer discussão sobre culpa da separação, tão somente vinculando também no momento da separação os cônjuges ao socorro mútuo, à mútua assistência, ante a vedação legal de que uma pessoa enriqueça, sem causa, à custa de outra pessoa. Madaleno adverte:

Portanto, os alimentos compensatórios em nada se confundem com a pensão alimentícia, e sua origem remonta ao direito francês, quando aquele país, no ano de 1975, apagou a discussão da culpa para o estabelecimento da prestação alimentar compensatória ${ }^{3}$ e passou a considerar o desequilíbrio econômico de forma objetiva, com total independência da culpa ou inocência do cônjuge credor de alimentos, consagrando, definitivamente, a irrelevância da culpa e a importância apenas da ruptura do relacionamento, evitando qualquer dramatização causal nos conflitos conjugais. Com o estabelecimento dos alimentos compensatórios o

3 ALBERDI, Beatriz Saura. La pensión compensatória; critérios delimitadores de su importe y extensión. Valencia: Tirant lo Blanch, 2004, p. 32. 
direito francês admitiu que o cônjuge credor percebesse alimentos mesmo quando exercesse vínculos de trabalho, os quais não supõem a privação do direito aos alimentos compensatórios pelo fato de o credor dos alimentos ter uma fonte própria de proventos, posto que importa apurar se, com o rompimento da relação, instalou-se uma visível disparidade na condição de vida de um dos cônjuges em confronto com a do outro e, destarte, proteger o consorte mais débil economicamente. Tampouco adianta afirmar que com a partilha dos bens os consortes se mantêm economicamente equilibrados, se com o marido, por exemplo, ficaram os bens rentáveis e com a pensão alimentícia a ex-esposa sequer consegue preservar sua meação.

Não diz, portanto, com a responsabilidade pela separação, e, sim, com a vedação do enriquecimento sem causa e a tentativa de reigualar as condições de vida do casal que se separou.

\section{TIPOS DE ALIMENTOS COMPENSATÓRIOS}

Parte da doutrina divide os alimentos compensatórios em razão do desequilíbrio financeiro e da administração dos bens comuns.

Rolf Madaleno distingue esses últimos dos alimentos compensatórios denominando-os de ressarcitórios ou indenizatórios (Carvalho, 2014).

A indenização pelo uso exclusivo ou pela administração exclusiva de bem comum possui previsão legal no artigo $4^{\circ}$, parágrafo único, da Lei $\mathrm{n}$. $5.478 / 78$, que determina a fixação de alimentos provisórios nos seguintes termos:

Art. $4^{\circ}$. Ao despachar o pedido, o juiz fixará desde logo alimentos provisórios a serem pagos pelo devedor, salvo se o credor expressamente declarar que deles não necessita.

Parágrafo único. Se se tratar de alimentos provisórios pedidos pelo cônjuge, casado pelo regime da comunhão universal de bens, o juiz determinará igualmente que seja entregue ao credor, mensalmente, parte da renda líquida dos bens comuns, administrados pelo devedor.

Em que pese a expressa previsão de fixação de renda mínima para os casos em que o casal tenha sido casado no regime de comunhão de bens - regime matrimonial legal à época da edição da lei - em análise sistêmica é possível a aplicação da referida legislação sempre que houver bens comuns administrados somente por um dos cônjuges.

\section{PROBLEMAS A SEREM RESOLVIDOS}

A primeira questão que surge quando se fala em alimentos compensatórios é a possibilidade, ou não, de prisão civil do devedor de alimentos que descumprir com a sua obrigação. 
Havendo divergência quanto à natureza da obrigação - a maior parte da doutrina e da jurisprudência entende que teria uma natureza indenizatória questiona-se a possibilidade da constrição física do devedor de alimentos dessa natureza.

Filiamo-no ao entendimento majoritário no STJ, tomando como exemplo o complexo julgamento do RHC 28.853/RS, em que a Corte Superior concluiu que a natureza indenizatória desse tipo de alimentos impede a aplicação do disposto no artigo 733 do Código Civil e, portanto, deve ser repelido o pedido de prisão do devedor.

No caso levado ao exame do STJ, "executa-se a verba correspondente aos frutos do patrimônio comum do casal a que a autora faz jus, enquanto aquele se encontra na posse exclusiva do ex-marido". Essa verba vem fundada na solidariedade, muito menos na mútua assistência conjugal, mas no direito de meação. Quer dizer: evita-se que, enquanto pendente a partilha, que haja enriquecimento sem causa em favor de um dos cônjuges, especificamente aquele que detém a posse dos bens comuns.

A outra questão que exsurge quanto aos alimentos compensatórios tem a ver com a possibilidade de transmissão de alimentos desse tipo.

Simão (2013) trata dessa importante ponderação:

Os alimentos, historicamente, são considerados intransmissíveis (art.
402 do Código Civil/16). Isso quer dizer que, com a morte do alimentante ou do alimentário, a obrigação se extingue, seguindo a máxima latina: alimenta solum debentur pro tempore, quo alimentandus vivit, et pro tempore decurso post ejus mortem ad haeredes non transmitantur (apud Yussef Cahali, op. cit., p. 48). Contudo, o artigo 1.700 do Código Civil determina que a obrigação de prestar alimentos transmite-se aos herdeiros do devedor, na forma do art. 1.694. Essa transmissibilidade tem sua explicação. Se os alimentos decorrem da solidariedade familiar e garantem o direito à vida, nada mais lógico que, com a morte do devedor, os alimentos continuem a ser prestados pelo espólio deste. É claro que a interpretação harmônica do sistema exige duas conclusões: 1) a transmissão se dá com relação às prestações vencidas $\mathrm{e}$ vincendas e; 2) a responsabilidade se dá nas forças da herança, não atingindo os bens pessoais dos herdeiros do devedor (art. 1.792 do CC).

Asseverando que a hipótese não possui natureza alimentar, segue o doutrinador:

Em se tratando de valor pago porque um dos cônjuges está administrando os bens comuns e recebendo seus frutos, essa importância segue exatamente o dito anteriormente: pode ser cedida, pode ser transmitida, pode ser objeto de renúncia, pode ser compensada, sofre os efeitos da supressio, e, também, o valor pode ser penhorado pelos credores do cônjuge que o recebe. Por fim, caso o valor seja fixado pelo juiz, a 
pretensão de cobrança prescreve em três anos conforme o caput do art. 206, parágrafo $3^{\circ}$ do Código Civil, que cuida do enriquecimento sem causa e não no prazo especial do parágrafo segundo do art. 206.

Vê-se que a importância do questionamento diz diretamente com os efeitos da obrigação, envolvendo a possibilidade de prisão, renúncia, transmissão, penhora, compensação e prescrição. À falta de legislação específica, necessitamos da jurisprudência para definir questões de extrema relevância para a aplicação da matéria.

\section{JURISPRUDÊNCIA EMBLE- MÁTICA DE CONCESSÃO DE ALIMENTOS COMPENSATÓRIOS O caso Collor Rosane}

Um dos casos mais importantes para o Direito de Família no ano de 2013 foi o julgamento do recurso especial relativo aos alimentos compensatórios envolvendo um ex-presidente do Brasil. A despeito do segredo de justiça que envolve o processo, que impediu a página eletrônica do Superior Tribunal de Justiça de divulgar o número do recurso, a situação de fato foi amplamente divulgada nos meios de comunicação, sem qualquer restrição ao nome das partes, a saber: Fernando Affonso Collor de Mello, ex- -presidente da República e atualmente senador da República pelo estado de Alagoas, e Rosane Brandão Malta, ex-primeira-dama brasileira.

Como não é possível a consulta aos autos eletrônicos, deve-se confiar no resumo divulgado na página eletrônica do tribunal e dele extrair os elementos descritivos do caso, que foi decidido pela $4^{\mathrm{a}}$ Turma do STJ, na sessão de 12 de novembro de 2013:

a) $\mathrm{O}$ senador Fernando Collor e sua ex-mulher Rosane Malta casaram-se no ano de 1984, sob o regime de separação convencional de bens. Eram as segundas núpcias de Fernando Collor e as primeiras de Rosane Malta, que ainda não havia completado 20 anos.

b) Durante o matrimônio, Fernando Collor foi governador do estado de Alagoas e depois eleito presidente da República. Seu mandato foi abreviado em razão do impeachment ocorrido em 1992. O casal manteve-se unido, apesar de diversas crises divulgadas na imprensa, até o ano de 2005. A separação foi litigiosa e cumulada por uma oferta de alimentos por Fernando Collor, no valor de $\mathrm{R} \$ 5,2$ mil, a qual foi contestada por Rosane Malta, que pretendia receber $\mathrm{R} \$ 40$ mil.

c) A sentença do juízo de primeiro grau, da Justiça alagoana, deferiu 
a Rosane Malta dois automóveis e $\mathrm{R} \$ 900$ mil em imóveis, além de uma pensão de alimentos no valor de 30 salários mínimos mensais, pagáveis enquanto lhes fossem necessários. A matéria foi devolvida ao Tribunal de Justiça de Alagoas, que, ao apreciar a apelação do ex-marido, "reduziu a pensão mensal para 20 salários mínimos pelo período de três anos, mantendo a sentença no restante". Houve recurso de embargos infringentes, após o que "o tribunal estadual restabeleceu o valor de 30 salários mínimos e afastou a limitação de três anos".

d) No STJ, a matéria foi apreciada em Recurso Especial, tendo como argumentos da parte do ex -marido, o fato de que não houve pedido expresso de alimentos compensatórios pela ex-mulher e, por essa razão, o julgamento fora extra petita. Rosane Malta argumentou que ela se casou aos 19 anos e permaneceu casada ao lado do marido por 22 anos, sem que o ex-marido houvesse colocado qualquer bem em seu nome, $o$ que implicaria "abuso de confiança" por parte de Fernando Collor. e) No julgamento do recurso, entendeu-se que: i) é possível a atribuição de alimentos compensatórios, na hipótese de quebra do equilíbrio econômico-financeiro decorrente da separação; ii) os alimentos devem ser fixados em prazo de três anos, a contar do trânsito em julgado da decisão; iii) dever-se-ia admitir a transferência de bens de um cônjuge a outro, nos termos do quanto estabelecido nas instâncias ordinárias.

Quanto ao direito aos alimentos compensatórios, o relator ministro Antonio Carlos Ferreira não foi acompanhado pelo ministro Marco Buzzi, em cujo voto dissidente se salientou que a transferência de bens seria contrária ao pacto antenupcial.

No que se refere ao lapso temporal de três anos resultou das discussões durante a sessão de julgamento, com o voto prevalente dos ministros Antonio Carlos Ferreira (relator), Luís Felipe Salomão e Raul Araújo, sob o fundamento de que esse tempo seria suficiente para a preparação do alimentando para a nova realidade econômica advinda do fim da pensão e sua eventual preparação para o mercado de trabalho. Discordaram os ministros Marco Buzzi e Isabel Gallotti, para quem seria extremamente difícil para uma mulher beirando os 50 anos aprender um trabalho/ofício e ganhar a vida com seu próprio esforço. Notadamente depois de se ter casado aos 19 anos e haver dedicado grande parte de sua vida no acompanhamento de seu ex-cônjuge em suas atividades políticas que, como se sabe, exigem muito do tempo da família. 
Desse julgado, extrai-se questões relevantíssimas para o Direito de Família. Por exemplo, os limites à interferência judicial em um regime de separação convencional de bens; a extensão temporal do direito aos alimentos; a existência dos chamados "alimentos compensatórios" como figura jurídica autônoma no ordenamento jurídico e a formulação de um princípio do equilíbrio econômico nas relações conjugais.

\section{CONSIDERAÇÕES FINAIS}

Tanto os alimentos transitórios como os alimentos compensatórios vinculam-se ao princípio constitucional da dignidade da pessoa humana e, portanto, possuem um alicerce constitucional a lhes dar sustentação.

Os alimentos transitórios, mais difundido e melhor aceitos diante de sua transitoriedade, proporcionam um resgate da dignidade pessoal daquele cônjuge que, por circunstâncias que foram estabelecidas na constância do casamento, ao findar a união não conseguiria se sustentar sem a ajuda financeira do outro. Além da transitoriedade preestabelecida na fixação do pensionamento, mudanças nas condições de possibilidade e necessidade podem determinar a extinção da obrigação. Funda-se em um princípio basilar de solidariedade social que não se extingue com o término da união.
Bem mais controvertido é o dever de prestar alimentos compensatórios.

Mesmo que a doutrina majoritária se coloque de forma favorável aos alimentos compensatórios, muitas críticas vem sofrendo o instituto.

Revela-se, primeiramente, a peculiaridade de os alimentos compensatórios não se tratarem, propriamente, de prestação de alimentos, tendo em vista o caráter indenizatório da obrigação. Além disso, não se funda em critérios binários de possibilidade e necessidade, com o que difere substancialmente das demais prestações alimentares.

Por outro lado, mesmo que seja estabelecida a necessidade de compensação de um cônjuge para o outro, a compensação não decorre de culpa ou do regime de bens adotado pelos cônjuges, mas, sim, é baseado em dois critérios básicos: a existência de um casamento ou união estável e, à data da separação, do surgimento de uma situação de desigualdade patrimonial capaz de provocar um prejuízo ou dano em um dos cônjuges, cuja causa imediata é a própria separação.

Entendemos que o instituto dos alimentos compensatórios tem especial e relevante aplicação quando o vínculo afetivo é desfeito após longa união e na época em que o casal já está há muito tempo junto, muitas vezes já na terceira idade, e um dos cônjuges se dedicado integralmente ao papel estabelecido na união, em função da família, sem que tivesse investido 
no seu desenvolvimento ou aperfeiçoamento profissional. Respeita-se, assim, o projeto familiar estabelecido pelo casal, bem como se promove uma segurança pessoal e patrimonial nas relações familiares.

Longe de estarem dirimidas as dúvidas referentes aos alimentos compensatórios, acreditamos que à jurisprudência e à doutrina cumpre o papel de estabelecer os contornos do instituto até que legislação específica regule a matéria.

Até lá, impõe-se o uso moderado do instituto, aplicável apenas excepcionalmente, para que, na busca da manutenção da dignidade da pessoa humana e com base nos princípios de solidariedade, mútua ajuda e vedação ao enriquecimento injustificado, não se produza exatamente o efeito repelido.

\section{REFERÊNCIAS}

ALVES, José Carlos Moreira. Direito romano. Rio de Janeiro: Forense, 2008

BRASIL, CONSTITUIÇÃO FEDERAL. Disponível em: http://www. planalto.gov.br/ccivil_03/Constituicao/Constituicao.htm. Último acesso em: 28/06/2014.

. Código Civil de 1916. Disponível em: http://www.planalto. gov.br/ccivil_03/Leis/1930-1949/ L0883.htm. Último acesso em: 26/06/2014

Lei $n .6 .515$, de 26 de dezembro de 1977. Dispõe os casos de dissolução da sociedade conjugal e do casamento, seus efeitos e respectivos processos, e dá outras providências. Disponível em: http://www.planalto.gov.br/ ccivil_03/leis/16515.htm. Último acesso em: 28/06/2014.
BOBBIO, Norberto. El Tiempo de los Derechos. Madrid: Ed. Sistema, 1991.

CAHALI, Yussef Sahid. Dos Alimentos. 6. ed. São Paulo: RT, 2009.

CARVALHO, Dimas Messias de. Direito das Famílias. 3. ed. Lavras: Unilavras, 2014.

DIAS, Maria Berenice. Manual de Direito das Famílias. 6. ed., rev., atual. e ampl. São Paulo: Revista dos Tribunais, 2010.

DIAS, Maria Berenice; CUNHA PEREIRA, Rodrigo da (Coord.). Direito de família e o novo Código Civil. Belo Horizonte: Del Rey, 2001. GILISSEN, John. Introdução Histórica ao Direito. 4. ed. Lisboa: Fundação Calouste Gulbenkian, 2003. FACCHIN, Luiz Edson. Famílias: Entre o público e o privado. In: Anais do VIII Congresso Brasilei- 
ro do Instituto Brasileiro de Direito de Família - IBDFAM. Disponível em: http://www.ibdfam. org.br/publicacoes/anais/detalhes/608/VIII\%20Congresso\%20 Brasileiro\%20de \%20Direito\%20 de $\% 20$ Fam $\%$ C3\%ADlia $\% 20 \% 20$ Fam\%C3\%ADlia:\%20entre\%20 o \% 20 p \% C $3 \%$ B A blico $\% 20$ e $\% 20 \mathrm{o} \% 20$ privado. Acesso em: 26.06.2014.

FARIAS, Cristiano Chaves de. A Tutela Jurídica da Confiança Aplicada ao Direito de Família. In: Anais do V Congresso Brasileiro do Instituto Brasileiro de Direito de Família - IBDFAM. Disponível em: http://www.ibdfam.org.br/publicacoes/anais/detalhes/714/V\%20 Congresso $\% 20$ Brasileiro $\% 20$ de $\% 20$ Direito $\% 20$ de $\% 20$ Fam $\% \mathrm{C} 3 \%$ ADlia. Acesso em: 26.06.2014.

FIUZA, Cezar. Curso Completo de Direito Civil. 12. Ed. Belo Horizonte: Editora Del Rey.

GOMES, Orlando. Direito de Familia. Rio de Janeiro: Forense, 1999. MADALENO, ROLF. Obrigação, Dever de Assistência e Alimentos
Transitórios. In: http://www. rolfmadaleno.com.br/novosite/ conteudo.php?id=37. Acesso em: 27/06/2014.

LEITE, Eduardo Oliveira. Temas de direito de família. São Paulo: RT, 1994.

PEREIRA, Caio Mário da Silva. Instituições de Direito Civil. Direito de Família, V. V, p. 18-19, 2012.

RIZZARDO, Arnaldo. Direito de Família. Rio de Janeiro: Forense, 2006.

SIMÃO, José Fernando. Alimentos compensatórios: desvio de categoria e um engano perigoso. Revista do Instituto de Direito Brasileiro. Ano 2, n. 6, p. 5.841-5.850, 2013.

THEODORO Jr., Humberto. Curso de Direito Processual Civil: Processo de Execução e cumprimento da sentença, processo cautelar e tutela de urgência, 41. ed. Rio de Janeiro: Forense, 2007.

VENOSA, Sílvio de Salvo. Direito civil: direito de família. 8. ed. 475 p. (Coleção direito civil; 6). São Paulo: Atlas, 2008. 